\title{
KEANEKARAGAMAN JENIS KELELAWAR (Chiroptera) DI HUTAN KOTA TELUK AKAR BERGANTUNG KABUPATEN KETAPANG
}

\author{
(Diversity of Bats (Chiroptera) in The Urban Forest of Teluk Akar Bergantung District of \\ Ketapang)
}

\author{
Lana Trecyana, Iswan Dewantara, Erianto \\ Fakultas Kehutanan Universitas Tanjungpura, Jalan Imam Bonjol Pontianak, 78124 \\ E-mail: lanatrecya@gmail.com
}

\begin{abstract}
Bats (Chiroptera) are the only mammals that can fly. Bat habitats are in caves, large trees in the forest, hollow trees, coconut trees, banana trees and roofs of buildings. Bats are nocturnal, they forage at night and sleep during the day by hanging upside down. Teluk Akar Bergantung has a generally flat and swampy topography, with a small portion submerged in water. Various types of trees have grown, one of them is Beringin/Kayu Are, which is where bats live. Bats play a role in the balance of ecosystems as seed dispersers, flower pollinators, insect controllers and guano producers. Based on the potential in this area, the research aims to collect data on various types of bats in Teluk Akar Bergantung, Ketapang regency, West Kalimantan. The method used is catch and release method using mist nest. Data analysis of the research used bats identification guide written by Suyanto (2001) entitled "Kelelawar di Indonesia" and "Panduan Lapangan Mamalia di Kalimantan, Sabah, Sarawak dan Brunei Darussalam" by Payne et. al (2000), diversity index (H'), equitability index (e), dominance index and species richness $(d)$. The result of research obtained 14 individuals consist of 6 species (Vampir palsu (Megaderma spasma), Codot mini (Cynopterus minutus), Codot krawar (Cynopterus bracyothis), Codot horsfield (Cynopterus horsfieldii), Codot kecil kelabu (Pentethor lucasii) and Codot pisang-coklat (Macroglossus minimus), belonging to 2 families (Pteropodidae and Megadermatidae). Diversity index is in the medium category $(1,47)$, the equitability index is in the high category $(0,82)$, no type of bats that dominates $(0,31)$ and the species richness is in medium category $(2,79)$.
\end{abstract}

Keywords: bats, diversity, Teluk Akar Bergantung, urban forest

\section{PENDAHULUAN}

Kelelawar merupakan satu-satunya anggota kelompok mamalia yang dapat terbang dan menempati urutan kedua terbesar jumlah jenisnya setelah ordo binatang pengerat (Rodentia). Di dunia terdapat 18 suku, sekitar 192 marga dan 977 jenis kelelawar (Suyanto 2001). Berdasarkan jenis makanannya, kelelawar dapat dibagi menjadi dua kelompok besar yakni kelelawar pemakan buah (Megachiroptera) dan kelelawar pemakan serangga (Microchiroptera). Menurut
Suyanto (2001) Indonesia kurang lebih memiliki 205 jenis kelelawar dari sembilan suku yang terdiri atas 72 jenis kelelawar pemakan buah (Megachiroptera) dan 133 jenis kelelawar pemakan serangga (Microchiroptera).

Teluk Akar Bergantung merupakan tipe hutan dataran rendah, berdasarkan laporan kegiatan Tata Batas Definitif Tahun 2002 Kawasan Hutan Kota Teluk Akar Bergantung mempunyai panjang $5.121 \mathrm{~m}$ dengan luas 91 ha. Secara administratif pemerintahan hutan kota ini 
terletak di desa Sukaharja Kecamatan Delta Pawan Kabupaten Ketapang. Teluk Akar Bergantung memiliki topografi yang umumnya datar serta berawa dengan sebagian kecil terendam air. Sungai yang mengalir pada kawasan ini adalah Sungai Pawan dan Sungai Sentap (Dinas Kehutanan Ketapang 2004). Jenis-jenis vegetasi yang tumbuh didalam kawasan ini yakni Meranti (Shorea sp), Beringin/kayu are (Ficus benjamina), Merawan (Hopea sp), Ramin (Gonystylus sp), Nyatoh (Palaquium sp), Pulai (Alstonia sp), Jelutung (Dyera costulata), Rengas (Gluta renghas) dan sebagainya. Beberapa diantara pohon tersebut menjadi tempat bagi kelelawar untuk tinggal maupun mencari makan. Sebagai salah satu jenis satwa dalam ekosistem alam, kelelawar memiliki fungsi ekologis yang penting bagi ekosistem diantaranya untuk penyerbukan serta penyebaran biji juga pengendali hama. Keanekaragaman jenis kelelawar merupakan kekayaan sumber daya alam yang harus dilestarikan sehingga keseimbangan struktur hutan dapat terjaga dengan baik khususnya dalam hutan kota Teluk Akar Bergantung Kabupaten Ketapang. Berdasarkan potensi yang terdapat di kawasan ini maka dilakukan penelitian dengan tujuan untuk mendata berbagai macam jenis kelelawar yang ditemui di hutan kota Teluk Akar Bergantung.

\section{METODE PENELITIAN}

Penelitian ini dilakukan di Hutan Kota Teluk Akar Bergantung Kecamatan Delta Pawan Kabupaten Ketapang dengan waktu penelitian selama 3 minggu efektif di lapangan mulai dari 7 - 21 Juli 2018 .
Penempatan mistnet dilakukan secara purposive (sengaja) dengan mempertimbangkan tempat-tempat yang menjadi jalur kelelawar dengan dua kali ulangan. Tempat-tempat tersebut adalah di tepi sungai, pohon buah, dan dekat bangunan. Alat-alat yang digunakan dalam penelitian ini adalah peta, GPS, bambu/cerucuk untuk menopang mistnet, mistnet, tali rapia, sarung tangan, kaliper/penggaris untuk mengukur morfologi kelelawar, spidol untuk menandai tubuh kelelawar, timbangan untuk mengukur berat badan kelelawar, kantong kain untuk menyimpan kelelawar, senter, kamera, jam tangan, parang, atk, tallysheet, buku identifikasi kelelawar. Bahan yang diperlukan dalam penelitian ini adalah kelelawar sebagai objek untuk diteliti.

\section{Analisa Data}

Analisa data yang digunakan dalam penelitian ini adalah identifikasi jenis dengan mengacu pada buku identifikasi jenis kelelawar yakni panduan lapangan Kelelawar di Indonesia karangan Suyanto (2001) dan Panduan Lapangan Mamalia di Kalimantan, Sabah, Serawak dan Brunei Darussalam karangan Payne et. al (2000), indeks keanekaragaman jenis (H'), indeks keseragaman jenis (e), indeks dominansi (C), dan indeks kekayaan jenis (d).

\section{HASIL DAN PEMBAHASAN}

Berdasarkan hasil penelitian di hutan kota Teluk Akar Bergantung pada 3 lokasi yakni tepi sungai, pohon buah, dan dekat bangunan diperoleh kelelawar dari 2 suku berbeda yakni Megadermatidae dan Pteropopidae. Terdiri dari 6 jenis kelelawar dengan total individu sebanyak 
14 individu. Berdasarkan jenis pakannya, terdapat 1 jenis dari sub ordo Microchiroptera yakni Megaderma spasma dan 5 jenis dari sub ordo Megachiroptera yakni Cynopterus minutus, Cynoptrtus bracyothis,
Cynopterus horsefieldi, Pentethor lucasii dan Macroglossus minimus, dengan individu jantan 10 dan betina 4. Untuk lebih jelasnya dapat dilihat pada Gambar 1 .

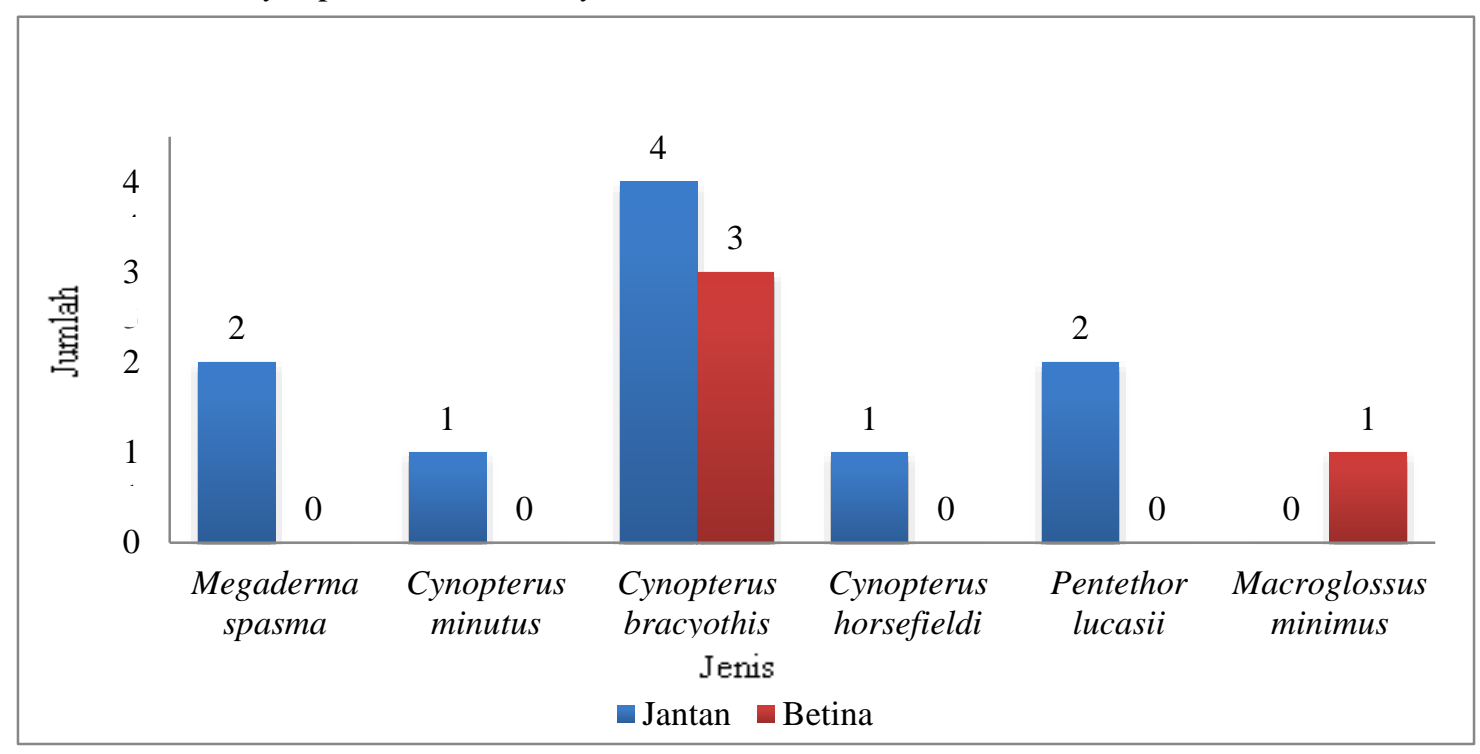

Gambar 1. Kelelawar yang Ditemui di Hutan Kota Teluk Akar Bergantung (Bats Found in The Urban Forest of Teluk Akar Berantung)

Indeks keanekaragaman jenis (H'), indeks keseragaman jenis (e), indeks dominansi (C), dan indeks kekayaan jenis (d) di hutan kota Teluk Akar Bergantung Kabupaten Ketapang

Keanekaragaman jenis kelelawar di hutan kota Teluk Akar Bergantung

Indeks keanekaragaman menyatakan keadaan populasi organisme secara sistematis agar mempermudah dalam menganalisis informasi jumlah individu masing-masing bentuk pertumbuhan/genus dalam komunitas habitat (Madduppa 2016). Indeks keanekaragaman pada keseluruhan lokasi penelitian mempunyai nilai 1,47 yang menunjukan bahwa lokasi penelitian masuk kategori sedang. Nilai indeks lokasi penelitian mengartikan bahwa kawasan hutan kota Teluk Akar Bergantung memiliki kondisi ekosistem yang seimbang serta produktivitas yang cukup, dengan demikian kawasan ini cocok untuk jenis kelelawar yang ditemui disana. Komunitas kelelawar di hutan kota tidak dapat dikatakan beranekaragaman jenis kelelawarnya namun juga tidak berarti ada jenis tertentu yang mendominasi, dengan demikian dimasukkan kedalam kategori sedang. Salah satu yang berpengaruh pada lokasi penelitian yakni tidak tersedianya pohon berbuah di dalam kawasan hutan kota Teluk Akar Bergantung yang menjadi sumber pakan bagi kelelawar, yang dapat mendukung dalam kelangsungan hidup kelelawar, sehingga kelelawar tidak dapat ditemui kelelawar pada bagian tengah kawasan hutan ini. Jumlah jenis yang tertangkap dari berbagai lokasi penelitian 
berpengaruh terhadap nilai indeks keanekaragaman jenisnya.

Keseragaman jenis kelelawar di hutan kota Teluk Akar Bergantung

Indeks keseragaman jenis menggambarkan penyebaran individu antar jenis yang berbeda dan diperoleh dari hubungan antara keanekaragaman (H') dengan keanekaragaman maksimalnya (Madduppa 2016). Umumnya, setiap kelelawar memiliki kemampuan beradaptasi dengan lingkungan termasuk gangguan dari predator maupun ketersediaan pohon buah sebagai sumber pakan. Jenis kelelawar pemakan buah (Megachiroptera) lebih banyak dijumpai jumlahnya daripada kelelawar pemakan seranggga (Microchiroptera). Kelelawar pemakan serangga (Microchiroptera) lebih sulit ditemui karena salah satu faktornya adalah tidak adanya gua yang merupakan tempat yang biasa digunakan oleh kelelawar ordo ini untuk tinggal serta pemasangan mistnet yang kurang tinggi dari tanah. Indeks keseragaman jenis kelelawar pada lokasi penelitian mempunyai nilai 0,82 yang menunjukan bahwa keseragaman populasi tinggi. Keseragaman jenisnya tinggi yang menandakan bahwa penyebaran jumlah individu tiap jenis pada lokasi penelitian sama, dengan demikian berarti tidak ada jenis tertentu yang mendominasi. Semakin kecil indeks keseragaman, semakin kecil pula keseragaman populasi, hal ini menunjukkan penyebaran jumlah individu setiap jenis tidak sama sehingga ada kecenderungan satu jenis kelelawar mendominasi.

\section{Dominansi jenis kelelawar di hutan kota Teluk Akar Bergantung}

Nilai indeks dominansi berkisar antara 1-0. Semakin tinggi nilai indeks tersebut, maka akan terlihat suatu jenis kelelawar yang mendominasi. Hasil analisa data menunjukkan bahwa pada lokasi penelitian mempuyai indeks dominansi mendekati nol dengan nilai dibawah 1. Nilai indeks dominansi lokasi penelitian sebesar 0,31, hal ini menunjukkan bahwa pada lokasi penelitian tidak terdapat jenis kelelawar yang mendominasi.

\section{Kekayaan jenis kelelawar di hutan kota} Teluk Akar Bergantung

Kekayaan jenis kelelawar menunjukkan adanya perbedaan di setiap lokasi pengamatan di kawasan hutan kota Teluk Akar Bergantung. Indeks kekayaan jenis kelelawar pada lokasi penelitian memiliki nilai 2,79 (lihat Gambar 2) yang menunjukkan bahwa kekayaan jenis kelelawar masuk kategori sedang. Kekayaan jenis dipengaruhi oleh total jenis dan total individu seluruh jenis dalam suatu habitat. Semakin banyak jumlah jenis dan jumlah individu yang ditemui pada suatu habitat maka akan semakin besar nilai kekayaan jenis pada lokasi tersebut. Sebaliknya, apabila jumlah jenis dan jumlah individu yang ditemui sedikit maka nilai kekayaan jenis nya masuk kategori rendah.

Untuk mengetahui keseluruhan indeks dari hasil yang telah dilakukan dapat dilihat pada Gambar 2. 


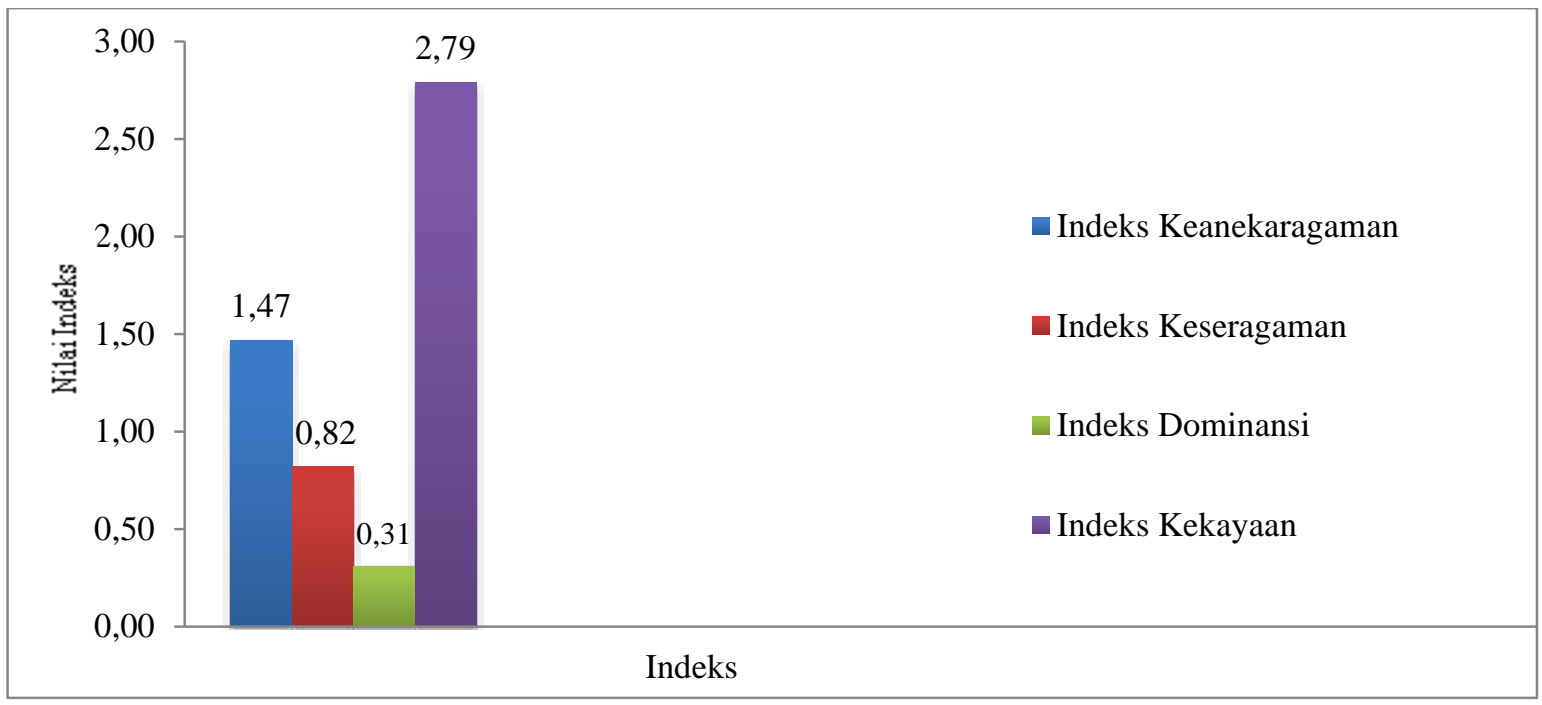

Gambar 2. Grafik indeks dominansi, indeks keanekaragaman, indeks keseragamanan dan indeks kekayaan jenis kelelawar di hutan kota Teluk Akar Bergantung

\section{Kesimpulan}

Berdasarkan penelitian yang telah dilakukan di Hutan Kota Teluk Akar Bergantung, terdapat 6 jenis kelelawar yakni Vampir Palsu (Megaderma spasma) Codot mini (Cynopterus minutus), Codot krawar (Cynopterus bracyothis), Codot horsfield (Cynopterus horsfield), Codot kecil kelabu (Pentethor lucasii), Codot pisang-coklat (Macroglossus minimus). Tidak ada jenis kelelawar tertentu yang mendominasi pada lokasi penelitian. Keanekaragaman jenis kelelawarnya sedang, keseragaman populasi nya termasuk tinggi, serta kekayaan jenisnya sedang.

\section{Saran}

Keberadaan kelelawar sangat bergantung pada ketersediaan pohon buah yang menjadi sumber pakan maupun tempat istirahat bagi kelelawar. Menambah jenis pohon buah seperti durian, matoa di dalam kawasan hutan kota akan lebih memperkaya jenis kelelawar yang ada disana. Untuk penelitian selanjutnya sebaiknya peletakkan mistnet harus lebih tinggi dari yang telah penulis lakukan, agar diperoleh kelelawar jenis pemakan serangga yang lebih beranekaragam. Sebaiknya melakukan pengamatan kelelawar pada saat musim buah tiba, agar diperoleh hasil tangkapan kelelawar yang lebih beranekaragaman.

\section{UCAPAN TERIMAKASIH}

Penulis mengucapkan terima kasih kepada orangtua serta COMDEV Universitas Tanjungpura yang telah memberikan bantuan moril maupun materil terhadap penelitian ini.

\section{DAFTAR PUSTAKA}

Dinas Kehutanan Kabupaten Ketapang. 2004. Rencana Umum Pembangunan dan Pengelolaan Hutan Kota Kabupaten Ketapang. Ketapang

Madduppa H. 2016. Modul Pelatihan: Teknik Analisis Kuantitatif Data Biologi Laut. Bogor: Institut Pertanian Bogor. 
JURNAL HUTAN LESTARI (2019)

Vol. 7 (1) : 198 - 203

Payne J, Francis CM, Phillips K, Kartikasari SN. 2000. Panduan Lapangan Mamalia di Kalimantan, Sabah, Serawak dan Brunei Darussalam. Bogor: Wildlife Conservation Society.
Suyanto A. 2001. Panduan Lapangan Kelelawar di Indonesia. Bogor: Pusat Penelitian dan Pengembangan Biologi - LIPI. 